\title{
Attentional requirements for object-location priming
}

\author{
GAIL MUSEN \\ Sun Microsystems, Inc., Burlington, Massachusetts \\ and \\ JEANNA VIOLA \\ Albert Einstein College of Medicine, New York, New York
}

\begin{abstract}
The purpose of the present experiments was to investigate whether a verbal and a spatial secondary task would disrupt priming for object-location associations. Symbols were placed one at a time in one of nine locations in a rectangle. Implicit memory was tested with a reaction time (RT) task. All symbols were placed in the same location of the rectangle across 10 trial blocks; then, all their locations were changed. Responses were made on the numeric keypad, which corresponded to the spatial locations used in the rectangle. A decrease in RTs across the first 10 trial blocks followed by an increase in RTs when the symbols changed locations would indicate priming for the associations. The results were that implicit memory for object-location associations was obtained under single-, but not under dualtask conditions. We have interpreted the results in terms of a working memory model that posits that implicit memory will suffer when cognitive resources are limited.
\end{abstract}

Research has shown that the division of attention during learning affects explicit memory performance under a wider set of circumstances than those under which it affects implicit memory performance (Jacoby, Woloshyn, \& Kelley, 1989; Mulligan \& Hartman, 1996; Musen, Siripant, Podemski, \& Kohn, 1998). Researchers have proposed that attention must be adequately allocated to presented stimuli during encoding to show evidence of explicit memory (Fisk \& Schneider, 1984), but that priming effects can be obtained without focused attention (Eich, 1984; but see Wood, Stadler, \& Cowan, 1997).

Explicit memory tests require participants to deliberately retrieve information about past events, whereas implicit memory tests measure memory indirectly by means of tests of perceptual identification (e.g., Jacoby \& Dallas, 1981), reading speed (Monti, Gabrieli, Wilson, \& Reminger, 1994; Moscovitch, Winocur, \& McLachlan, 1986; Musen, Shimamura, \& Squire, 1990), lexical decision (e.g., Scarborough, Cortese, \& Scarborough, 1977), and word-fragment completion (e.g., Graf, Mandler, \& Haden, 1982; Tulving, Schacter, \& Stark, 1982). In such tests, evidence for memory is inferred from the faster and more efficient processing of previously studied material relative to new material.

This research was supported by a mini-grant from Barnard College and National Science Foundation Grant 96-16323 to G.M. and was conducted while the first author was affiliated with Barnard College. We thank Tzipora Kohn, Lisa Podemski, and Sumanas Siripant for research assistance. Correspondence concerning this article should be addressed to G. Musen, Sun Microsystems, Inc., One Network Drive, MS UBURO2-201, Burlington, MA 01893 (e-mail: gail.musen@east. sun.com).
Most studies that have examined the effect of attention on implicit and explicit memory have used single-item stimuli (e.g., words, nonwords, or shapes presented in isolation), in which case there is only one study opportunity. These tests have shown that implicit memory effects (or priming effects) can be observed even when information is minimally attended to during study (Eich, 1984; Hawley \& Johnston, 1991; Kunst-Wilson \& Zajonc, 1980; Mandler, Nakamura, \& Van Zandt, 1987). Thus, one might conclude that priming effects occur with or without focused attention, whereas explicit memory effects require focused attention. However, recent studies on this topic have suggested that attention can influence priming effects when the learning or retrieval task requires participants to extract the conceptual characteristics of the stimuli (Mulligan, 1997; Mulligan \& Hartman, 1996), when study time is reduced in a perceptual-priming paradigm involving flanking digits (Ganor-Stern, Seamon, $\&$ Carrasco, 1998), or when associative stimuli are to be learned (Musen et al., 1998). Conceptual new-association priming depends on access to a word's meaning (Keane et al., 1997), whereas perceptual new-association priming depends on the physical aspects of the stimuli; perceptual new-association priming benefits when the stimuli to be associated are treated as a single object (Musen \& Squire, 1993a).

To demonstrate the effect of attention on conceptual priming performance, Mulligan (1997) manipulated attention by using various digit loads. Implicit memory was tested by using a category-exemplar generation task. It has been proposed that this task accesses the conceptual components of stimuli because the categorization of a word involves the identification of its meaning (Blaxton, 
1992). Mulligan reported that both explicit and implicit memory performance worsened under high attentional load conditions. However, although the high digit load condition completely eliminated implicit memory, explicit memory performance was still above chance (although it was significantly worse when the stimuli were fully attended). Thus, attentional resources seem to be necessary when the learning task is conceptual in nature.

Not only does conceptual item priming require more attentional resources than are required by perceptual item priming, conceptual new association priming also is more difficult to obtain than perceptual association priming. Thus far there have been no reports of conceptual associative priming, although many researchers have investigated it (e.g., Mayes \& Gooding, 1989; Paller \& Mayes, 1994; Schacter \& Graf, 1986; Shimamura \& Squire, 1989). In contrast, associative perceptual priming can occur under certain conditions, such as when lexical-decision (Goshen-Gottstein \& Moscovitch, 1995a, 1995b), color-naming (Musen \& O'Neill, 1997; Musen, Szerlip, \& Szerlip, 1999), and perceptual-identification tasks are used (Gabrieli, Keane, Zarella, \& Poldrack, 1997). When the study task does not emphasize these properties, or when the stimuli to be associated are difficult to conceive as a single object, associative priming is more difficult to obtain (cf. Gabrieli et al., 1997; Moscovitch et al., 1986, for evidence of associative priming; cf. Musen \& Squire, 1993b, for evidence against associative priming).

Importantly, when perceptual associative priming is obtained, it is often dependent on focused attention (Musen et al., 1998). Musen et al. found that priming effects suffered under conditions of attentional load. In a study by Musen (1996), associative-priming effects were examined for object-location stimuli. The results from these experiments strongly suggested an important role for attentional mechanisms, although attention was not manipulated directly. Because of the close resemblance of our study to the one reported by Musen, we will outline that study here. Symbols or letters were placed in one of nine locations in a rectangle, one object at a time. Each object was placed in the same location within the rectangle across 10 trial blocks, and then all the locations of the objects were changed at the 11 th trial block. The implicit task was varied across experiments by using either symbol, letter, or location naming. Thus, the task demands were varied by changing the stimuli (letters or symbols) or by changing the required task (symbol, letter, or location naming). Reduction of naming times was used as a measure of implicit memory. An increase in naming times between the 10th and 11 th trial block, when the objects changed locations, was taken as evidence that the associations were learned. The amount of priming obtained was found to depend on both the difficulty of the objects used and the required naming task. The pattern of results suggested that high explicit memory performance occurred when the task was relatively easy, and an observable priming effect occurred when the task engaged, but did not overtax, attentional resources.

Musen (1996) hypothesized that the required naming tasks coupled with the processing of the stimuli might compete for attentional resources in the same way as would a secondary task. In the present study we therefore manipulated attention directly, using two different secondary tasks (a verbal and a spatial task) in two separate experiments. The design was basically the same, except that only symbols were placed in the rectangles, and the required task was a keypress task in which the participants pressed a key on the $3 \times 3$ numeric keypad that corresponded to the location of the symbol in the rectangle.

Attentional control is thought to be exerted through a working memory system consisting of three subcomponents (Baddeley, 1992; Baddeley \& Hitch, 1974). Baddeley and his colleagues suggested that working memory is composed of a central executive that is used for reasoning and overseeing two slave systems. The two slave systems are the visuospatial sketchpad and the phonological loop. We attempted to overtax the visuospatial or phonological loop component of working memory by using a secondary task. To tax the phonological loop, a verbal secondary task was used in which a letter was placed under the rectangle on each trial; across trials, two related sentences were formed, which the participants were to write down after the final trial. To tax the visuospatial sketchpad module of working memory, a spatial task was used in which a blue circle occupied one of the locations not used by the symbol. Because of the structure of our learning task, it seemed likely that both tasks might interfere with learning because the primary keypress task had a strong spatial component that depended on matching spatial locations in the rectangle with a particular key on the numeric keypad. The primary task also had a strong verbal component, because nameable stimuli were placed in the rectangle. As Musen (1996) pointed out, even when the required task does not encourage participants to name stimuli, it is likely that they do so covertly. In her study, she found that under location-naming instructions reaction times (RTs) were slower when symbols were placed in the rectangle than when letters were. Thus, although the task was identical in both cases, the type of object placed in the rectangle appeared to influence naming times (RTs averaged $1,078 \mathrm{msec}$ when symbols were used and $889 \mathrm{msec}$ when letters were used).

Each experiment included a single-task condition in which the participants were presented a letter or an asterisk on each trial but were told to ignore them. Recognition tests were also conducted in each condition of both experiments so that a general comparison between explicit and implicit memory performance could be made. However, the different designs across tasks makes it difficult to directly compare the results. Because we evaluated two different types of secondary tasks, it was important to ascertain whether they differed in difficulty. To do that, we tested several participants on both secondary tasks prior 
to the experiment to ensure that RTs in each task were equivalent.

\section{EXPERIMENT 1}

In this experiment, we examined whether priming for object-location associations could be obtained under a verbal secondary task condition. Symbols were placed one at a time in one of nine locations in a rectangle. Both single- and dual-task conditions were conducted. In the dual-task condition, a letter was placed under the rectangle on each trial. The participants were asked to keep track of the letters and were told that, across trials, two sentences would be presented and that they should try to remember them.

We were interested in whether the addition of a secondary task would have the same effects as increasing the attentional demands indirectly varying the difficulty of both the stimuli and the naming task. Musen (1996) observed that whether or not explicit and implicit memory were observed or not depended on the overall difficulty of these two variables. She suggested that in order to find object-location priming, attention needs to be engaged, but not overtaxed. Evidence for explicit memory was found when the task was very easy, requiring little or no attention, and disappeared under a lighter attentional load than did priming. In the present study, we used a keypress task instead of a naming task because of its simple mapping of location in the rectangle with location on the numeric keypad. We thought that the addition of a secondary task would reduce available resources for learning the object-location associations and possibly eliminate or reduce priming, as compared with the single-task condition. In the single-task control condition, symbols were placed in rectangles and a letter appeared beneath the rectangle; however, the participants were told to ignore the letters since they were meant for participants in a different experimental condition. In addition, we conducted a four-alternative, forced-choice recognition task in both the single- and dual-task conditions so that we could improve our understanding of how attention affects explicit memory. However, it is difficult to compare implicit and explicit memory performance, owing to the presence of the secondary task in all phases of the implicit memory task, as compared with the presence of only the encoding phase in the explicit memory task.

\section{Method}

Participants. Eighty participants from Barnard College and $\mathrm{CO}$ lumbia University (12 men and 68 women) served in the experiment for course credit. All participants were naive with respect to the purpose of the experiment and were between the ages of 17 and 27 years $(M=20.1)$. Forty participants served in the explicit memory condition (20 in the single-task condition and 20 in the dual-task condition), and 40 participants were tested in the implicit memory condition (20 in the single-task condition and 20 in the dual-task condition).

Materials. Nine symbols (!,@,\#,\$,\%,\&,*,?,+) were used. Each symbol was placed in one of nine locations of a rectangle measuring $16.0 \times 20.5 \mathrm{~cm}$. The symbols measured approximately $0.7 \times$
$0.7 \mathrm{~cm}$. The locations were equally spaced and appeared in the upper left, upper center, upper right, middle left, middle center, middle right, lower left, lower center, and lower right locations in the rectangle. All symbols appeared once before any were repeated. Each block consisted of nine trials with no breaks between blocks. The final item in each block was never the same as the first item in the next block. Thus, identical symbols did not appear consecutively. The stimuli were presented on a VGA monitor controlled by a 486 IBM computer. In the single-task condition, the participants were told to ignore the letter. In the dual-task condition, the participants were told that across trials, two sentences would be presented and that they would be asked to report them in writing later. Three dashes under the rectangle (i.e., - - - ) signified the end of a word. In addition, in both the single- and the dual-task conditions, a letter measuring 0.6 $\times 0.6 \mathrm{~cm}$ was centered under the rectangle on each trial and was placed $0.5 \mathrm{~cm}$ below the rectangle. Each symbol was placed in the same location of the rectangle for the first 10 trial blocks, after which all the locations were switched. For example, the symbol $\$$ might always appear in the upper left corner of the rectangle. Every time the symbol $\$$ occurred for the first 10 trial blocks, it would always appear in the upper left corner of the rectangle until the 11 th trial block (Trial 91), in which it (and all the other symbols) would be switched to a new location and remain in that location for the remaining 5 trial blocks.

Design and procedure. Type of test (implicit or explicit) was varied between subjects and block was varied within subjects. RT to locate the symbol was the implicit memory measure, and recognition memory accuracy was the explicit measure of memory.

The participants were given nine practice trials with the keypress task, which required them to press a corresponding key on the numeric keypad. For this task, nine letters were placed in one of the nine locations, one at a time. Each location and letter was used once. The purpose of this practice task was to familiarize the participants with the task of mapping the location in the rectangle with the corresponding location on the numeric keypad. In the actual experiment, one symbol appeared in one of the nine locations of the rectangle during each trial, and the participants were to press the corresponding key as quickly as possible. The symbol remained visible until the participants responded. The two sentences presented were She went to the library to study because her classes were difficult and She received high grades on her exams, but her social life suffered. The first sentence ended before the symbols changed locations, so that the only difference between the 10th and 11 th trial blocks was that the object-location associatioins were recombined.

The group of participants in the explicit memory condition were given a recognition memory test after the first 10 trial blocks. They were not informed in advance that their memories would be tested. On each trial, they were asked simply to press the key that corresponded to the location that was occupied by the symbol (as in the implicit memory task). In the recognition task, a rectangle was presented to the participants, and four symbols appeared in each location. The participants were asked to circle which symbol appeared in that location previously. The participants in the secondary task, explicit memory condition were also asked to write down the sentence that had been presented to them. The participants in the singletask condition were asked to ignore the letters below the rectangle.

\section{Results}

In Figure 1, RTs (in milliseconds) across the 15 trial blocks are shown. We used $p=.05$ as the significance level for all comparisons. First, we performed an overall analysis of variance (ANOVA) across both the singleand dual-task conditions for the first 10 trial blocks and the final 5 trial blocks. For the first 10 trial blocks, we found no significant differences between groups or trial blocks and no interaction $(p s>.11)$. For the final 5 trial 


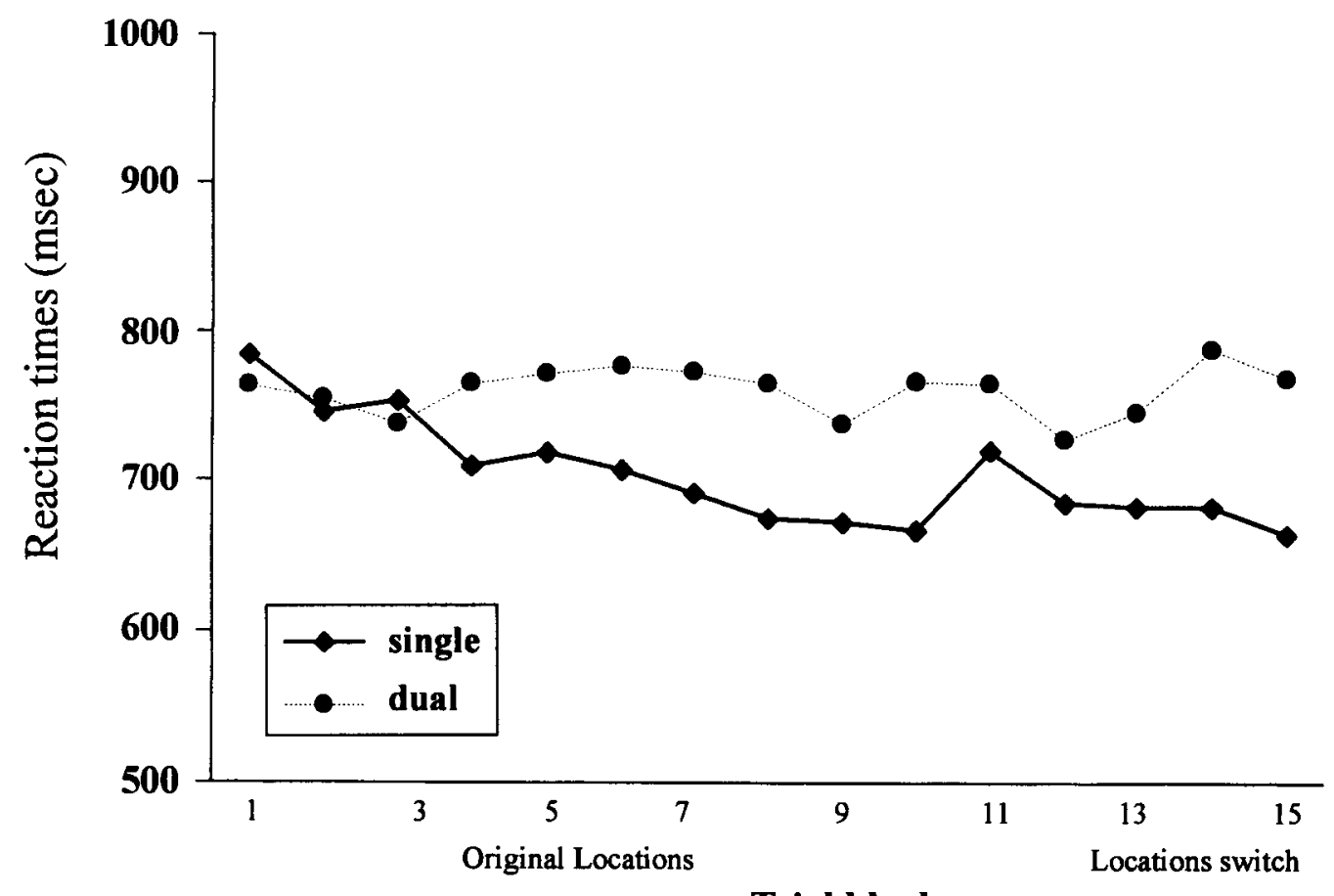

Trial blocks

Figure 1. Reaction times across 15 trial blocks under both single- and verbal secondary-task conditions. Symbols change locations on Trial Block 11.

blocks, we found near significant effects of both group and block, and a nearly significant group $\times$ block interaction $(p s<.09)$. Our original question was whether there would be learning across trial blocks for the singleand dual-task conditions, separately; the following analyses addressed this question.

Single-task condition. We found a significant effect of block for the first 10 trial blocks $[F(1,38)=5.4$, $\left.M S_{\mathrm{e}}=5,691.7\right]$ and for the final 5 trial blocks $[F(4,76)=$ 4.2, $\left.M S_{\mathrm{e}}=1,963.0\right]$. In addition, a trend analysis revealed evidence of a linear trend for the first 10 trial blocks $\left[F(1,19)=31.3, M S_{\mathrm{e}}=8,101\right]$ but not for the final 5 trial blocks $(p=.48)$. RTs decreased between the $1 \mathrm{st}$ and 10th trial block $[t(19)=5.0 ; 774 \mathrm{msec}$ and $666 \mathrm{msec}$, for 1 st and 10th blocks, respectively]. In addition, there was a significant increase in RTs for the single-task condition on the 11 th trial block, during which all the symbols changed locations $[t(19)=3.2 ; 666 \mathrm{msec}$ and $720 \mathrm{msec}$, for the 10th and 11 th trials, respectively]. Responses were $97.7 \%$ accurate and did not differ across blocks. This finding suggests that the associations were learned, since RTs were disrupted when the object-location associations were changed. Finally, there was a significant difference between the 11 th trial block and the 15 th trial block, indicating that some learning occurred in the final five trial blocks.

Dual-task condition. There were no significant effects for either the first 10 or the final 5 trial blocks for the dual-task condition, and there was no evidence for a linear trend for either set of trial blocks in the dual-task condition ( $p s>.18)$. Additionally, there were no differences between the 1st and 10th trial blocks, the 10th and 11 th trial blocks $(p=.96)$, or the 11 th and 15 th trial blocks $(p=.31)$. Thus, no learning of the associations appears to have occurred during the experiment. Responses were $96.2 \%$ accurate and did not differ across blocks. There was no significant difference in accuracy between the singleand dual-task conditions.

Explicit memory. The participants scored $80 \%$ in the single-task condition and $60.5 \%$ in the dual-task condition. Both these scores were significantly above chance $(25 \%)$, and performance was significantly better in the single-task condition than in the dual-task condition $[t(20)=5.5]$.

\section{Discussion}

The results of this experiment demonstrate that priming of object locations was eliminated under secondarytask conditions, although priming was evident in the singletask condition. Thus, object-location associations appear to have been affected by the attentional demands imposed by the addition of a secondary task, as well as when the task was made more difficult by the introduction of a more difficult behavioral task or more difficult stimuli (Musen, 1996).

\section{EXPERIMENT 2}

In this experiment, we investigated whether associative priming could occur under a spatial secondary task. The same primary stimulus was used as in Experiment 1, with 
the same keypress task. Because of the spatial component in the primary task, it was expected that the secondary task would also eliminate implicit memory for the associative information, and we expected explicit memory performance to be similar to that observed in Experiment 1.

\section{Method}

Participants. Eighty participants (21 men and 59 women) were tested in Experiment 2. None had served in Experiment 1. All participants were naive to the purpose of the experiment and were between the ages of 18 and 30 years $(M=20.9)$. Forty participants served in the explicit memory condition (20 in the single-task condition and 20 in the dual-task condition), and 40 were tested in the implicit memory condition ( 20 in the single-task condition and 20 in the dual-task condition).

Materials. The materials were the same as those used in Experiment 1 , except that instead of a letter being placed beneath each rectangle, a blue circle was placed in one of the locations of the rectangle that was not occupied by the symbol. The circle measured $0.6 \times 0.6 \mathrm{~cm}$.

Design and procedure. Type of test (implicit or explicit) was varied between subjects, and block was varied within subjects. The implicit and explicit memory tests were identical to those in Experiment 1 .

The procedure was identical to that in Experiment 1, except that rather than being asked to keep a sentence in mind while carrying out the keypress task, the participants were asked to remember where the blue circle had appeared. After every three trials, they were asked to record on a grid where the circles had been. In the singletask condition, the participants were also shown the circles but were told to ignore them; after every three trials, the participants were shown three sets of two numbers that indicated which three circles to mark on the grids. For example, the numbers 1,3 would indicate that the participant should circle the third circle in the first row, and the numbers 2,2 would indicate that the participant should mark the second circle in the second row. This was done so that the partici- pants in the single-task condition had to stop the task every three trials, in a similar manner as in the dual-task condition.

\section{Results}

In Figure 2, the RTs (in milliseconds) across the 15 trial blocks are shown. First, we performed an overall ANOVA across both the single- and dual-task conditions for the first 10 trial blocks and the final 5 trial blocks. For the first 10 trial blocks, we found significant differences between groups and between blocks, and an interaction between group and block. For the final trial blocks, we found similar results, except that the effect of block approached significance $(p=.07)$. The overall difference between the two conditions was diminished because in the 11 th trial block, the RT increased in the single-, but not the dual-, task condition. Next, we analyzed whether performance improved across both sets of trial blocks for the single- and dual-task conditions, separately.

Single-task condition. We found a significant effect of trial block for the first 10 trial blocks $[F(9,171)=$ $\left.10.5, M S_{\mathrm{e}}=10,654\right]$. In addition, a trend analysis revealed a significant linear trend $\left[F(1,19)=24.0, M S_{\mathrm{e}}=\right.$ $38,070]$. No higher order trends were significant. This finding shows that not only did the RTs decrease across trial blocks, but they did so in a linear fashion. In addition, there was a significant effect of block for the final trial blocks $\left[F(4,76)=4.7, M S_{\mathrm{e}}=2,985\right]$. The decrease in RTs across blocks also followed a linear trend $[F(1,19)=$ $\left.7.8, M S_{\mathrm{e}}=5,444\right]$. RTs decreased between the first and the 10 th block $[t(19)=4.4,929 \mathrm{msec}$ and $732 \mathrm{msec}$, respectively]. There was a significant effect of changing the locations of the symbols, indicated by the analysis be-

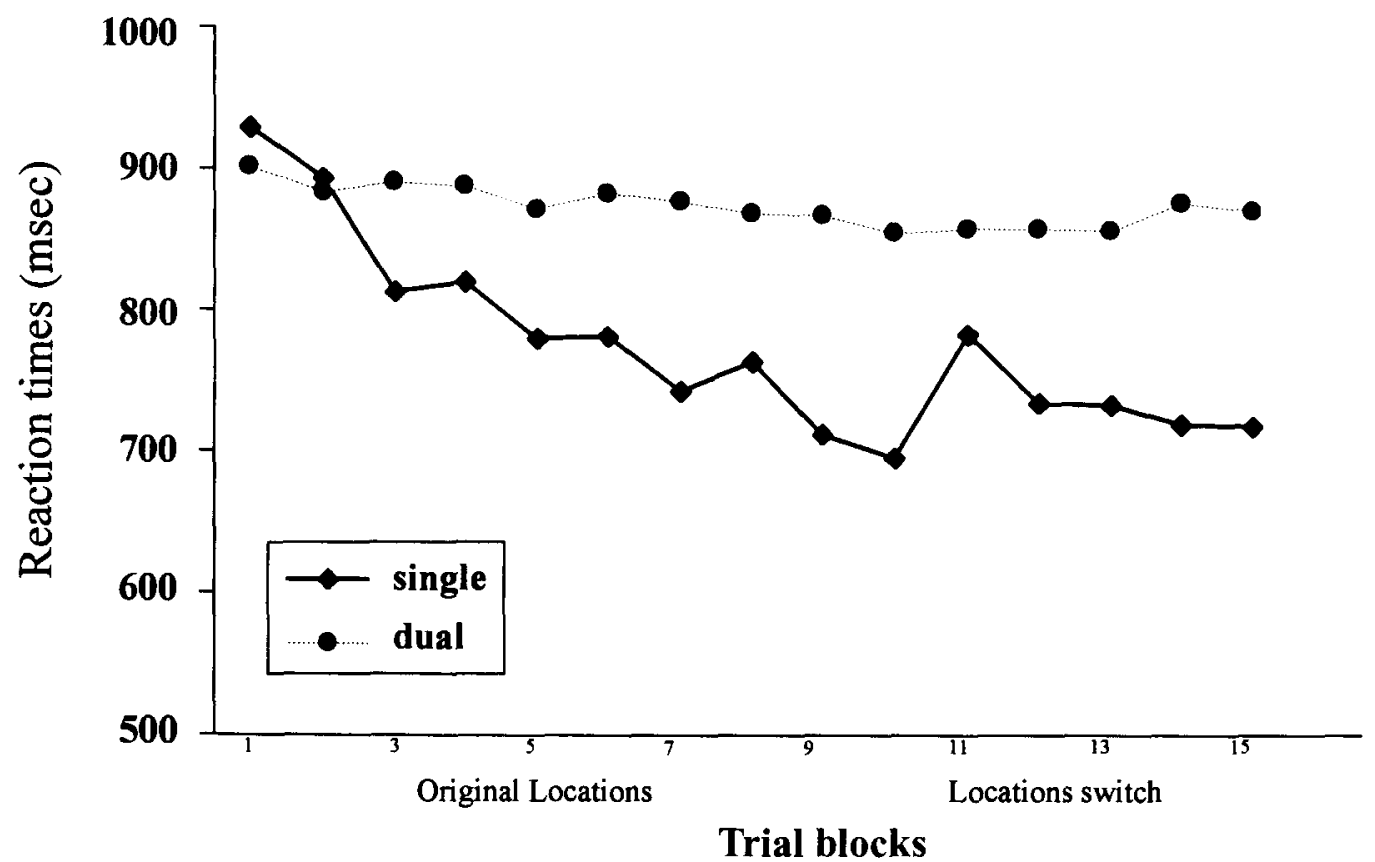

Figure 2. Reaction times across 15 trial blocks under both single- and spatial secondary-task conditions. Symbols change locations on Trial Block 11. 
tween the 10th and 11 th trial blocks $[t(19)=2.1]$. RTs were $732 \mathrm{msec}$ and $782 \mathrm{msec}$ for Trial Block 10 and Trial Block 11 , respectively. In addition, the $\mathrm{RT}$ s decreased between Trial Block 11 and Trial Block $15[t(19)=2.9]$. RTs were $782 \mathrm{msec}$ and $717 \mathrm{msec}$, for the 11 th trial block and the 15 th trial block, respectively. Responses were $97.2 \%$ accurate and did not differ across blocks.

Dual-task condition. There were no significant block effects for either the first 10 or the final 5 trial blocks $(p s>.18)$, although there was a significant linear trend for the first 10 trial blocks $\left[F(1,19)=6.3, M S_{\mathrm{e}}=4,504\right]$. There was a significant decrease in RTs between the 1st and the 10th trial blocks $[t(38)=3.2 ; 902 \mathrm{msec}$ and $854 \mathrm{msec}$, for Ist trial block and 10th trial block, respectively]. However, no other comparisons reached significance. The lack of an increase in between Trial Block 10 and Trial Block $11(p=.81)$ indicates that no associative priming occurred. Responses were $99.3 \%$ accurate and did not differ across blocks.

Explicit memory. The participants scored $77.2 \%$ in the single-task condition and $58.3 \%$ in the dual-task condition. Both of these scores were better than chance, and performance was significantly better in the single-task condition than in the dual-task condition $[t(38)=5.1]$.

\section{Discussion}

As in Experiment 1, we found that the secondary task eliminated associative priming, although a pronounced associative-priming effect was observed in the single-task condition. Because the primary task had both strong verbal and spatial components, it is not surprising that the results from both experiments are so similar. However, this does tell us that object-location priming is quite susceptible to attentional demands. Not only did such priming disappear when the stimuli or behavioral task was made more difficult, but the increase of attentional demands by means of several types of secondary tasks also served to reduce the priming effects.

\section{GENERAL DISCUSSION}

The present experiments demonstrate that dividing attention can eliminate priming for new associations. In contrast, under single-task conditions, robust associative learning was obtained. The improvements that were demonstrated in the single-task condition could have been due either to general learning of the keypressing task or to specific learning of the associations between the objects and their locations, or to some combination of the two. We know that specific learning of new associations occurred because of the increase in RTs between the 10 th and 11 th trial blocks. This comparison is critical because it is at this point in the experiment that all the symbol locations were switched. Thus, if learning of the objectlocation associations had taken place, RTs to location, which was then occupied by a different symbol, should have been slowed since the participants might have grown to expect a different stimulus in that location.
It is not surprising that both secondary tasks produced an elimination of the priming effect observed in the singletask conditions. Because it is likely that the participants had inadvertently accessed the names of the symbols (see Musen, 1996), it would seem, by analogy, that our primary task might have had a verbal component that could have competed with the verbal secondary task for phonological loop resources. Similarly, because the keypress task and the presentation of a stimulus in a particular location both required spatial processing they would place demands on the visuospatial sketchpad component of working memory. Therefore, a spatial secondary task, which also competes for these same resources, would interfere with learning.

The results of this study, together with those of Musen (1996), suggest that task difficulty is an important variable in the priming of object-location associations. The Musen study showed that when difficulty was imposed by using less easily named stimuli (symbols) coupled with an attention demanding location naming task, implicit memory for associations did not occur. In the present study, when difficulty was imposed by the addition of a secondary task, a similar finding was obtained. Task difficulty has also been demonstrated to be important in the determination of performance levels in implicit-learning tasks, such as sequence learning. It has been shown that when the sequence structure is unique, such that one can predict the upcoming stimulus, implicit learning can occur under divided-attention conditions. However, when the sequence is ambiguous in such a way that a particular item could be followed by more than one stimulus, implicit learning cannot occur under divided-attention conditions (Cohen, Ivry, \& Keele, 1990; Curran \& Keele, 1993; Stadler, 1995).

The present experiments and those of Musen (1996) bear some resemblance to sequence-learning experiments in that they all involve the accumulation of learning across trials; also, the difficulty of the tasks in all these experiments was varied by the manipulation of the stimuli or the nature of the learning task. An important difference between sequence learning and the type of task described in the present paper is that in sequence-learning tasks, association learning occurs across trials, but in our study, it occurs within trials. The design of our experiments did not permit the participants to predict upcoming stimuli; thus the RTs were affected by how fast the participants processed the stimulus that was visible, not by the participants' expectations of upcoming stimuli.

In most studies in which explicit and implicit memory have been tested under divided-attention conditions, it has been found that explicit memory performance is more affected by reduction in cognitive resources than is implicit memory performance. In our study, explicit memory performance was well above chance in both experiments, although performance was substantially reduced in the dual-task condition when compared with the single-task condition. However, it is important to note that the explicit and implicit memory tasks were not com- 
pletely comparable, because there was no secondary task in the retrieval portion of the explicit memory task. This difference could have led to better performance in the explicit memory condition than in the implicit memory condition. In fact, Craik, Govoni, Naveh-Benjamin, and Anderson (1996) reported that the division of attention during retrieval has little effect on recognition memory for individual items. It is possible that recognition performance of associative material would have been more affected, but the present experiments did not incorporate that manipulation and, thus, cannot adequately speak to the issue.

Another reason why the explicit memory performance might have been better is that there were multiple repetitions of the same stimuli. Repetitions are known to influence explicit memory more than implicit memory (Musen \& Treisman, 1990; Schacter, Cooper, Delaney, Peterson, \& Tharan, 1991). This may be because when stimuli are repeated in a distributed fashion, in which the same stimuli do not appear consecutively, there may be increased attention to subsequent repetitions if the participant recognizes it as one seen previously but already forgotten (Shaughnessy, 1976; Shaughnessy, Zimmerman, \& Underwood, 1972). In addition, the stimuli might be processed more meaningfully and with more effort, leading to a sturdier memory trace (Jacoby, 1978). Explicit memory processes are also believed to be more flexible than implicit memory processes, and they are available to multiple response systems (Squire, Knowlton, \& Musen, 1993). Thus, the increase in retrieval routes and the enrichment of memory traces are more likely to benefit explicit memory performance than implicit memory performance. This benefit for explicit memory performance was not found in the Musen (1996) study. This may have been because the location naming task in that experiment was too difficult and led to chance performance. It might be that the participants' attempts to name the locations (e.g., upper left, middle center) interfered with their mapping the location to the object. In contrast, the present keypress task was simple and would not have introduced this added burden. RTs for the two types of task support this suggestion (RTs averaged $770 \mathrm{msec}$ in the single-task conditions in both the present experiments and $1,078 \mathrm{msec}$ in the Musen study).

In summary, our results show that when divided attention occurs during encoding, a toll is taken on associative priming, even when multiple study opportunities are given. Both the verbal and the spatial secondary task eliminated associative priming, suggesting that the primary task had important verbal and spatial components. It is possible that the secondary task exerted its influence by using resources from working memory modules (i.e., visuospatial sketchpad or phonological loop) that were necessary for learning the associations. The division of resources between two similar tasks led to the elimination of associative priming. Whether explicit memory processes are similarly affected by attentional load still needs to be investigated further. In the explicit memory conditions of the present experiments, attention was divided during encoding, but not during retrieval, so firm conclusions cannot be drawn. The relationship between learning associations across trials, such as in a sequence-learning paradigm, and learning associations within trials, as in the present experiments, needs to be carefully studied to determine whether there might be variables that influence one type of learning but not another.

\section{REFERENCES}

BADDEley, A. [D.] (1992). Working memory. Science, 225, 556-559. BadDEley. A. D., \& Hitch, G. J. (1974). Working memory. In G. H. Bower (Ed.), The psvchologv of learning and motivation (Vol. 8, pp. 47-90). New York: Academic Press.

Blaxton, T. A. (1992). Dissociations among memory measures in memory-impaired subjects: Evidence for a processing account of memory. Memory \& Cognition, 20, 549-562.

COHEN, A., IVRy, R. I., \& KEELE, S. W. (1990). Attention and structure in sequence learning. Journal of Experimental Psvchologv: Learning. Memorv, \& Cognition, 16, 17-30.

Craik, F. I. M., Govoni, R., Naveh-Benjamin, M., \& Aniderson, N. D. (1996). The effects of divided attention on encoding and retrieval processes in human memory. Journal of Experimental Psychology: General, 125, 159-180

Curran, T.. \& KeEle, S. W. (1993). Attentional and nonattentional forms of sequence learning. Journal of Experimental Psychology: Learning, Memory, \& Cognition, 19, 189-202.

Eı('H. E. (1984). Memory for unattended events: Remembering with and without awareness. Memorv \& Cognition, 12, 105-111.

Fisk, A. D. \& SchNeIDER, W. (1984). Consistent attending versus consistent responding in visual search: Task versus component consistency in automatic processing development. Bulletin of the Psvchonomic Society, 22, 330-332

Gabrieli, J. D. E., Keane. M. M., Zarei.la. M. M. \& Pol.drack, R. A. (1997). Preservation of implicit memory for new associations in global amnesia. Psychological Science, 8, 326-329.

Ganor-Stern, D., Seamon. J. G., \& Carrasc (O, M. (1998). The role of attention and study time in explicit and implicit memory for unfamiliar visual stimuli. Memory \& Cognition, 26, $1187-1195$.

Goshen-Gottstein, Y., \& Moscovitch. M. (1995a). Repetition priming effects for newly formed associations are perceptually based: Evidence from shallow encoding and format specificity. Journal of Experimental Psuchology: Learning, Memorv, \& Cognition, 21, 1249-1262.

Goshen-Gottsiein. Y.. \& Moscovitch. M. (1995b). Repetition priming for newly formed and preexisting associations: Perceptual and conceptual influences. Journal of Experimental Psychology: Learning. Memory, \& Cognition, 21, 1229-1248.

Graf, P., Mandlek, G., \& Haden, P. (1982). Simulating amnesic symptoms in normal subjects. Science, 218, 1243-1244.

HAWI.EY, K. J., \& JOHNSTON. W. A. (1991). Long-term perceptual memory for briefly exposed words as a function of awareness and attention. Journal of Experimental Psychologv: Human Perception \& Performance, 17, 807-815.

JACOBY, L. L. (1978). On interpreting the effects of repetition: Solving a problem versus remembering a solution. Journal of Verhal Learning \& Verbal Behavior, 17, 649-667.

JACOBY, L. L.. \& DALlas, M. (1981). On the relationship between autobiographical memory and perceptual learning. Journal of Experimental Psvchologv: General, 110, 306-340.

Jac OBY, L. L., WOLOSHYN, V., \& Kel.,EY, C. (1989). Becoming famous without being recognized: Unconscious influences of memory produced by dividing attention. Journal of Experimental Psvchologv: General, 118, $115-125$. 
Keane, M. M., Gabrieli, J. D. E., Monti, L. S., Fleishman, D. A., CANTOR, J. M., \& Noland, J. S. (1997). Intact and impaired conceptual memory processes in amnesia. Neuropsychology, 11, 59-69.

KUNST-WILSON, W. R., \& ZAJONC, R. B. (1980). Affective discrimination of stimuli that cannot be recognized. Science, 207, 557-558.

Mandler, G., Nakamura, Y., \& VAN ZandT, B. J. S. (1987). No specific effects of exposure on stimuli that cannot be recognized. Journal of Experimental Psychology: Learning, Memory, \& Cognition, 13, 646-648.

MAYES, A. R., \& GoODING, P. (1989). Enhancement of word completion priming in amnesics by cuing with previously novel associates. Neuropsychologia, 27, 1057-1072.

Monti, L. A., Gabrieli, J. D. E., Wilson, R. S., \& Reminger, S. L. (1994). Intact text-specific implicit memory in patients with Alzheimer's disease. Psychology \& Aging, 9, 64-71.

Moscovitch, M., Winocur, G., \& Mclachlan, D. (1986). Memory as assessed by recognition and reading time in normal and memoryimpaired people with Alzheimer's disease and other neurological disorders. Journal of Experimental Psychology: General, 115, 331-347.

Mulligan, N. W. (1997). Attention and implicit memory tests: The effects of varying attentional load on conceptual priming. Memory \& Cognition, 25, 11-17.

Mulligan, N. W., \& Hartman, M. (1996). Divided attention and indirect memory tests. Memory \& Cognition, 24, 453-465.

MUSEN, G. (1996). Effects of task demands on implicit memory for object-location associations. Canadian Journal of Experimental Psychology, 50, 104-113.

MUSEN, G., \& O'NeILL, J. E. (1997). Implicit memory for nonverbal associations. Journal of Experimental Psychology: Learning, Memory, \& Cognition, 23, 1192-1202.

Musen, G., Shimamura, A. P., \& Squire, L. R. (1990). Intact textspecific reading skill in amnesia. Journal of Experimental Psychology: Learning, Memory, \& Cognition, 16, 1068-1076.

Musen, G., Siripant, S., Podemski, L., \& Kohn, T. (1998). Associative priming for words and shapes under dual-task conditions. Paper presented at the Annual Meeting of the Psychonomic Society, Dallas.

MUSEN, G., \& SQuiRE, L. R. (1993a). Implicit learning of color-word associations using a Stroop paradigm. Journal of Experimental Psychology: Learning, Memory, \& Cognition, 19, 789-798.

Musen, G., \& SQuire, L. R. (1993b). On the implicit learning of novel associations in amnesic patients and normal subjects. Neuropsychology, 7, 119-135.

Musen, G., Szerlip, J. S., \& Szerlip, N. J. (1999). Role of familiarity and unitization on new-association priming. Journal of Experimental Psychology: Learning, Memory, \& Cognition, 25, 275-283.

Musen, G., \& Treisman, A. (1990). Implicit and explicit memory for visual patterns. Journal of Experimental Psychology: Learning, Memory, \& Cognition, 16, 127-137.

Paller, K. A., \& MaYes, A. R. (1994). New-association priming of word identification in normal and amnesic subjects. Cortex, 30, 53-73.

Scarborough, D. L., Cortese, C., \& Scarborough, H. S. (1977). Frequency and repetition effects in lexical memory. Journal of Experimental Psychology: Human Perception \& Performance, 3, 1-17. Schacter, D. L., Cooper, L. A., Delaney, S. M., Peterson, M. A., \& Tharan, M. (1991). Implicit memory for possible and impossible objects: Constraints on the construction of structural descriptions. Journal of Experimental Psychology: Learning, Memory, \& Cognition, 17, 3-19.

SChaCter, D. L., \& Graf, P. (1986). Preserved learning in amnesic patients: Perspectives from research on direct priming. Journal of Clinical \& Experimental Neuropsychology, 6, 727-743.

Shaughnessy, J. J. (1976). Persistence of the spacing effect in free recall under varying incidental learning conditions. Memory \& Cognition, 4, 369-377.

Shaughnessy, J. J., Zimmerman, J., \& Underwood, B. J. (1972). Further evidence on the MP-DP effect in free-recall learning. Journal of Verbal Learning \& Verbal Behavior, 11, 1-12.

Shimamura, A. P., \& Squire, L. R. (1989). Impaired priming of new associations in amnesia. Journal of Experimental Psychology: Learning. Memory, \& Cognition, 15, 721-728.

SQuire, L., KNOWLTON, B. J., \& MUSEN, G. (1993). The structure and organization of memory. Annual Review of Psychology, 44, 453-495.

STADLER, M. A. (1995). Role of attention in implicit learning. Journal of Experimental Psychology: Learning, Memory, \& Cognition, 21, 674-685.

Tulving, E., Schacter, D. L., \& Stark, H. (1982). Priming effects of word-fragment completion are independent of recognition memory. Journal of Experimental Psychology: Learning, Memory, \& Cognition, 8, 336-342.

WOOD, N. L., Stadler, M. A., \& Cowan, N. (1997). Is there implicit memory without attention? A reexamination of task demands in Eich's (1984) procedure. Memory \& Cognition, 25, 772-779.

(Manuscript received February 18, 1999; revision accepted for publication October 28,1999 .) 